\title{
Correction to: Spain, Catalonia, and the Supposed Authority of the Judiciary on the Self-Constitutive Moment in Adjudication
}

\section{Maurits Helmich ${ }^{1}$}

Published online: 24 September 2020

C) Springer Nature Switzerland AG 2020

\section{Correction to: Jus Cogens \\ https://doi.org/10.1007/s42439-020-00026-x}

\begin{abstract}
A typesetting error remained unnoticed. In the title given above, the main and sub-title of the article have been combined. The correct main title is "Spain, Catalonia, and the Supposed Authority of the Judiciary", while "On the Self-constitutive Moment in Adjudication" is the subtitle.
\end{abstract}

The original article has been corrected

Please excuse the mistake.

The publisher

The online version of the original article can be found at https://doi.org/10.1007/s42439-020-00026-X

\section{$\checkmark$ Maurits Helmich}

helmich@law.eur.nl

1 Erasmus School of Law, Rotterdam, Netherlands 